\title{
EXPERIENCES WITH TRAUMATIC PARAPLEGIC PATIENTS IN INDIA
}

\author{
By K. S. Masalawala, M.S., F.R.C.S. \\ Department of Traumatic and Orthopaedic Surgery, F. F. Hospital, Bombay, India
}

THIS paper is in many ways different from the others in as much as it does not deal with the scientific aspect of this problem, but rather the socioeconomic aspects of an affliction when suffered in a country which is a strange mixture of the modern and the ancient. While in the larger cities and hospitals we can muster quite a fair amount of modern technology and surgical skill, the day when the patient returns to his native village he is living under primitive conditions, lacking in such basic requirements as minimum home facilities, medical help, freedom of space to move at home, rutted and muddy roads unsuited for moving on wheelchairs or hand-operated tricycles. The lack of basic education in many patients makes the choice of a new vocation more difficult.

During the last four years a small paraplegic unit has been functioning at the J. J. Group of Hospitals. All 60 cases of traumatic paraplegia have been treated by us. Their age, sex and occupational status and cause of the accident are shown in Tables I-III.

Table I shows the age and sex incidence among our cases. As is usual the most common incidence is among males of $2 \mathrm{I}-30$ years. The overall picture also shows a considerable predominance of males over females, 92 per cent to eight per cent. The oldest patient was of 75 years and the youngest I I years.

TABLE I

Age and sex

\begin{tabular}{|c|c|c|c|}
\hline Age (years) & No. of cases & Male & Female \\
\hline IO-20 & I2 & 9 & 3 \\
2I-30 & 26 & 26 & - \\
$3 \mathrm{I}-40$ & $\mathrm{I} 7$ & I6 & I \\
$4 \mathrm{I}+$ & 5 & 4 & I \\
\hline Total & 60 & 55 & 5 \\
\hline
\end{tabular}

Oldest 75 years, youngest II years.

Table II shows the incidence of the causative factor in producing paraplegia. While the pattern of injury is fairly universal in most cases, I would like to mention especially the four cases of falls in a well. In the countryside in India many wells and water tanks exist with little or no protective fencing; some are completely dry while others have only a small quantitity of water at the bottom. Such wells produce major injuries as a result of falls in them. Of the four cases, three were 


\section{TABLE II}

Causative factors

Fall from a tree

Fall from an electric pole

Fall while playing

Falls at construction work

Vehicle accidents

Weight falling on back

Fall in a well

Stab wound

$$
\begin{array}{cc} 
& \text { I0 cases } \\
& 6 \text { cases } \\
\text { tric pole } & \text { I case } \\
\text { I6 cases } \\
\text { back } & \text { I5 cases } \\
& 7 \text { cases } \\
& 4 \text { cases } \\
\text { Total } & \text { I case } \\
\cline { 2 - 2 } \text { To cases }
\end{array}
$$

women. The practice of carrying heavy gunny-bags on the back by labourers while unloading a ship or truck has also produced casualties if the bag falls on the back rather than being placed on it. In other cases a slip or stumble by the labourer carrying the bag high up on the shoulder and neck results in a sharp flexion of the neck with dislocation of cervical spine and tetraplegia.

Table III is a study of the occupation of these 60 cases correlated to the actual causative factor of paraplegia. Thus there are two cases of men engaged as tree trappers for coconuts and toddy, five electricians who fell from a height while working on the electric pole, seven labourers injured while at their work and six professional bus and truck drivers who were involved in accidents on highways.

\section{TABLE III}

Occupational factors in paraplegia

\begin{tabular}{|l|c|c|}
\hline Occupation & $\begin{array}{c}\text { Total no. of } \\
\text { patients }\end{array}$ & $\begin{array}{c}\text { No. injured } \\
\text { at work }\end{array}$ \\
\hline Tree trappers & 2 & 2 \\
Electrical wiremen & 7 & 5 \\
Farmers & 9 & 5 \\
Labourers & I6 & I2 \\
City workers & I2 & - \\
Housewives & 5 & 6 \\
Motor bus drivers & 6 & $-\ldots$ \\
Students & 2 & - \\
Retired & I & 30 \\
\hline \multicolumn{1}{r|}{ Total } & 60 & \\
\hline
\end{tabular}

One of the major difficulties that we face is the time gap between the occurrence of injury and admission to our hospital (Table IV). The reasons for these are many. The majority of the injuries occur in smaller towns and villages with inadequate transport or medical facilities. Not only the patient but even the relatives have to arrange to come to the city by train or even in trucks often over a distance of 200 to 300 miles. Meanwhile the patient may be lying on any odd 
TABLE IV

Interval before admission

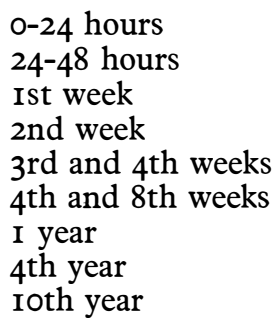

I 4 cases

3 cases

I 5 cases

I 2 cases

7 cases

3 cases

3 cases

2 cases

I case

Total 60 cases

pallet at home or in some village hospital, totally incontinent and receiving little or no nursing care; some medical man may have passed a catheter under difficult circumstances with a minimum of asepsis. The country hospitals have neither the staff nor the expertise to deal adequately with these cases. As will be seen from Table IV only I4 out of 60 cases or 26 per cent came to the hospital within 24 hours of the injury, and a further I 8 or 30 per cent (total 32 out of 60 or 51 per cent) within a week of the injury. All the rest came after considerable delay; 2I cases had developed one or more bedsores and 34 had urinary infection prior to admission. The cases in the last three groups which came one year, four years, and ten years after the original injury, were stabilised but had no opportunity for proper rehabilitation.

TABLE V

Level of lesion

\begin{tabular}{|l|c:c|}
\hline Level & Cases & Percentage \\
\hline D3-D8 & 9 & I5 \\
D9-DIO & 6 & I0 \\
DII-DI2 & 24 & 40 \\
LI-L2 & I8 & 30 \\
L3-L5 & 3 & 5 \\
\hline
\end{tabular}

The clinical and radiological pictures of these cases were classical. The level of the lesion is shown in Table V; only three cases had injuries between $\mathrm{L}_{3}$ and L5 level (Cauda Equina Syndrome). One such unusual case is briefly shown here.

A male patient aged 35 years, stone mason by occupation, was injured as a result of a heavy stone boulder falling on his back on I2 January I97I. He became immediately paralysed and was admitted to our unit four days later. On admission there was severe tenderness in lower back with a step ladder deformity at L4-5. There was a slight weakness of muscles proximal to the knee but complete paralysis of leg and foot muscles and loss of visceral control. X-rays showed a severe fracture-dislocation of $\mathrm{L}_{4}$ on $\mathrm{L}_{5}$, the break occurring through disc space. Open 


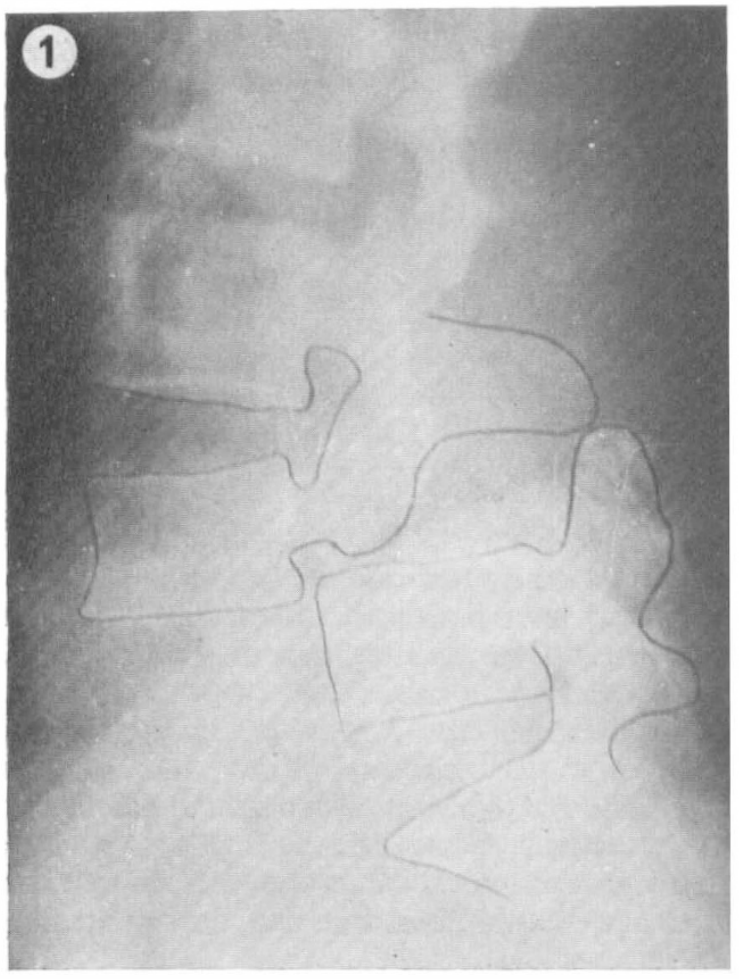

FIG. I

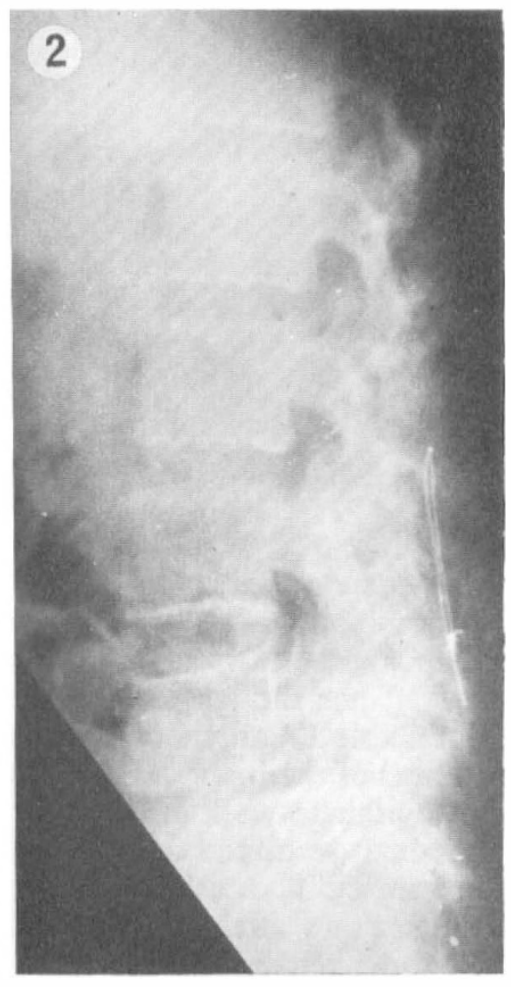

FIG. 2

reduction and fixation with wire was done (figs. I and 2). Three years later there has still been no improvement.

Similar cases have been reported by Holdsworth, Newman and Chacha. The neurological status on admission and at discharge is shown in Table VI. Fifty-six cases had complete paralysis including loss of visceral control, while in four cases the loss of motor and sensory function was below the knee. In only one of these four cases (L4-5 dislocation) was there loss of visceral control. Of the first group with total loss of function, no patient showed a complete recovery. However I2 patients showed partial recovery of lower abdominals and eight had developed an autonomous bladder. The small group of four cases with injury between L 3-5 level showed recovery of power in two cases but no recovery in two others. Bladder function was normal in three cases, the exception being the patient with $\mathrm{L}_{4}-5$ dislocation.

Among the complications of these cases I would just like to refer to the occurrence of myositis ossificans. In the earlier days of establishing our unit we enrolled the help of relatives to give passive movements, teaching them how to do so. In spite of emphasising the necessity of extreme gentleness and avoidance of any forcible movements, five cases developed myositis in rapid sucession. We have now stopped this practice with a much lowered incidence of this complication, even though the personnel at our disposal is less than optimum.

The treatment of these cases has been on the standard conservative lines. 


\section{TABLE VI}

Neurological picture

(A) Complete Loss

Complete recovery

Partial recovery

(B) Loss below Knee

Bladder Affected

Complete Recovery

No Recovery
56 cases
0 cases
I 2 cases

4 cases

I case

2 cases

2 cases

No surgery is done generally for the spinal lesion itself. However when necessary surgery for closing bedsores was done (Table VII). One of the most intractable bedsores are those at the back of heel, often associated with severe equinus and flexion deformities at knee in neglected cases. In some of these an amputation was carried out. However it was noted that if a bilateral amputation was done, the patient found it difficult to maintain his balance while sitting. Iliostomy for urinary complications, while desirable in many cases, has posed problems of the supply of bags and the lack of adequate facilities at home or at a near hospital for their maintenance. It has therefore been done in only three cases.

TABLE VII

$\begin{array}{lr}\text { Bed Sores } & \text { 2I cases } \\ \text { Healed under dressing } & \text { II cases } \\ \text { Split skin grafts } & 6 \text { cases } \\ \text { Rotation flaps } & 4 \text { cases }\end{array}$

The accent has naturally been on rehabilitation. For mobility, fitting of the patient with calipers and crutches, providing wheelchairs and/or tricycle chairs was a standard approach. Mechanised tricycle chairs are also available for use in cities like Bombay. However, what seemed feasible and proper while the patient was in hospital, often became difficult or impossible when the patient was discharged. If he returned to his home, especially in a village, the lack of manoeuvrable space combined with rough and uneven terrain made the use of both calipers and wheelchairs extremely difficult or even impossible. In some houses even the doors are too narrow to admit a wheelchair. Equally the country roads are unsuited for the use of the tricycle chair; under these circumstances it is not surprising that the patients discard their appliances and often become confined to a corner of their homes. We have now tried to ascertain the condition of stay in the home more accurately before supplying these appliances. In many cases a strong wooden chair fitted with castors and a foam rubber cushion serves far better.

The man living in the city also poses some problems. Although this group had generally some fixed accommodation, often this was on one of the upper floors of a building without any lift. Even if such a patient held or secured a job which required his going some distance to work, it was difficult or impossible for him to come down and go up every day. Often he also had the problem of finding a safe place to keep the tricycle chair. 
An even greater problem was the patient who had migrated into the city from the village to form its large labour force, being employed on construction of buildings, in docks etc. as a labourer. Almost all of them had no fixed place of residence living on footpaths or under whatever temporary shelter they could put up on a vacant spot of land. Often the man lived alone with no relatives, and none was forthcoming even after the accident. Their permanent rehabilitation is a problem which has so far proved unsurmountable. To discharge them often meant that the time, energy and money spent on them is, in the final analysis, wasted. After discharge they again rapidly deteriorate and come back with bedsores, urinary infection and general debility. Yet no acute hospital can keep them for ever. We are now pursuing the possibility of constructing a large vocational hostel somewhere outside the city.

Vocational training in new crafts was organised. After some thought we decided on three crafts; tailoring, cane-work and paper bags or fancy paper article making. It was felt that a man who could stitch a shirt, kurta, or pyjamas would find work even in the smallest village. The ordinary hand-operated sewing machine is simple to maintain and does not take up much space. Cane-work separately or along with tailoring was also taught and has proved a source of income to some patients. The totally illiterate with very poor motivation were taught how to make paper bags. The articles made by the patients were sold whenever possible and 50 per cent of the profits were distributed among those who had made them. However, many patients failed to utilise the skills they had acquired when they returned home.

Table VIII shows the rehabilitation pattern of our cases in terms of vocations. It is unfortunate that we do not know what has happened to $2 \mathrm{I}$ cases. The lack of adequate residential address and difficulties in communication due to apathy and illiteracy has resulted in our losing touch with a large number of our cases. This pattern is bound to remain.

TABLE VIII

Vocational rehabilitation

\begin{tabular}{lr}
$\begin{array}{l}\text { Tailoring } \\
\text { Minor Farming Chores }\end{array}$ & 9 cases \\
Absorbed by Companies & I2 cases \\
or shops & 4 cases \\
$\begin{array}{l}\text { Self employed } \\
\text { Continuing Studies }\end{array}$ & 5 cases \\
& 4 cases \\
\multicolumn{1}{c}{ Total } & 34 cases \\
$\quad$ Expired & 5 cases \\
Unknown & 2I cases
\end{tabular}

The problems of the paraplegic are immense. Were it not for the lead given by men like Guttmann, Hardy, Munro, Bors and Rogers, we would be groping even more in the dark. However, many factors are particular to a country; special occupations pose their own hazards; economic and educational levels affect the final outcome. Yet no patient needs the combined help of so many disciplines. The greater the deficit, the greater the challenge; we are trying to meet it. In the well-known words of Robert Frost: 
'The woods are gentle, dark and deep,

But I have many promises to keep,

And many miles to go,

Before I sleep.'

\section{REFERENCES}

Снасна, P. B. \& Loong, S. C. Unusual Neurological Damage after Fracture Dislocation of the Lumbar Spine.

HolDSWORTH, F. W. (I968). Fractures, dislocations and fracture dislocations of spine. F. Bone and foint Surg. $45 \mathrm{~B}, 6$.

Newman, P. H. (1968). Etiology of spondylotisthesis. F. Bone and foint Surg. 45, 39.

\section{Discussion}

Chairman. We now come to the papers of Dr. Chahal and Dr. Masalawala on the care of spinal injuries in India. I have been in India and can only confirm what these two colleagues have told us. I must say that my admiration for those who have started this new concept of treatment on the paralysed is indeed very sincere and very great. I only hope that the authorities will wake up to this problem because as you are now able to keep these people alive, this problem in India will increase very quickly. There is one point I would like to mention: how to prevent people in tropical areas from falling from trees and becoming paraplegics. I observed this to my great surprise in Malaysia in Kota Baru. The farmers have the same problem as you in tropical areas, where the people climb up to pick the coconuts and fall down and get a spinal injury. The farmers have introduced a most ingenious method to prevent these injuries-namely they train monkeys, and I have seen this myself. The monkey was tied to a long lead and at the first whistle climbed up very gently without any haste right up into the tree. When the farmer blew twice on his whistle, I saw this little animal take only ripe coconuts, twisting them slowly until they fell down. I suggest that you might introduce this as new preventative treatment in India!

DR. J. Silver (G.B.). I should like to ask the two speakers, in view of the discussion yesterday, what is their experience of pulmonary emboli? I would like to ask Dr. Masalawala, what happens to the people that you cannot discharge, what arrangements have you got? We all have this dreadful problem, and I was very interested in the confirmation of the view that ectropic calcification is related to unskilled or traumatic physiotherapy.

DR. A. S. ChaHAL (India). As I said yesterday, we have hardly come across pulmonary embolism. In the last three and a half years that I have been in this unit of about 200 patients, nobody has died of pulmonary embolism, and clinically only one patient had it, but he had a congenital heart disease, so my physician said it had nothing to do with the type reported from other countries.

Sir Ludwig, I hope you are not advising me to tell my Generals to employ some monkeys in the Army! (Interruption from Sir Ludwig-'Why not?!').

Unskilled physiotherapists - that was a very apt remark. When I took over the unit I stopped the physiotherapists doing vigorous treatment which was producing the trauma leading to ossification and you will be happy to know that during the last three years we have had no more than three cases of ossification since we stopped vigorous massage, electric stimulators and vigorous passive movements of the hip joints in the first few weeks after injury. I found that this is better and it is only the skilled physiotherapist who knows. I always insist on them bending the legs to $90^{\circ}$ and no more.

DR. K. S. Masalawala (India). Coming to your remarks about monkeys, Sir 
Ludwig-yes, I suppose it would be a good idea of we could find enough monkeys but we have exported so many to various countries that we are getting short of them ourselves!

Sir LUdWIG. ChaIRMan: I would like to make a comment with regard to the final resettlement of the paraplegics in India. I feel very strongly, having regard to the difficulties in discharging the patients to their villages, that the answer in India is exactly as it was in England in and immediately after the war, to set up hostels. I am very glad to hear that the hostel in Poona is already contemplated. That is where the authorities could really do something about it and to set up colonies in some areas for paraplegics. That has already been tried in Uganda before General Amin took over and proved highly successful.

Since yesterday I have been thinking about the question of thrombosis and emboli, and you just confirmed that in your country you hardly know it. I can also confirm this from Ethiopia, Egypt and other tropical countries. The question arises-and this is a matter where research could be carried out systematically-how far in the tropical countries the vasomotor control is so adjusted that this does not occur? This is a new idea which I had from all that was said yesterday. In other words, the blood circulation and their innervation must be so adapted through the continuous heat and humidity that in paralysed patients, the emergency vasomotor control is immediately present and prevents the clotting of the vessels. Now this would be an interesting subject for research both in tropical and in other countries. For instance, in the south of the U.S.A. you also have sub-tropical climates and the same applies to the Middle East. I hope that one day someone will come and tell us not only about the mechanism of this problem but also how to prevent this serious complication.

DR. Chahal (India). Regarding the development of homes, in addition to the one in Poona another is on the way near Delhi and the third one is a Red Cross Home in Bangalore down south, so the army feels this will cater for our needs for the next five years. Cheshire Homes have been doing a good job, they have been accepting both ex-servicemen and civilians. So there is a nucleus existing: all we are doing, Sir, with your good advice, is creating further problems by giving them more life and healthy paraplegics, which I am sure we will gradually find a way.

Dr. MASalawala (India). You were asking Sir Ludwig, what happens to the patients after they are discharged? When we have rehabilitated some of them and once the relatives have seen that they can look after themselves to a fair extent, they are prepared to have them back. Some of the patients have gone back to live with their families and added to the income of the family as a whole. In our countries, fathers, married sons, etc., are still living together in one house, and every member is expected to contribute towards the income of the family. But once they can do this we have found that some of them are returning and have found employment in their own shops and factories and so on.

ChaIRMAN. Its points clearly to how important education of society is in our work. You heard yesterday how some units invite the relatives to come and be trained there by the staff. That will of course spread, and I wish you the best of luck in the great work you are doing. 